\title{
First Degree Family History Cancer Negative
}

National Cancer Institute

\section{Source}

National Cancer Institute. First Degree Family History Cancer Negative. NCI Thesaurus.

Code C160166.

The parents, siblings or children of an individual have no history of cancer. 